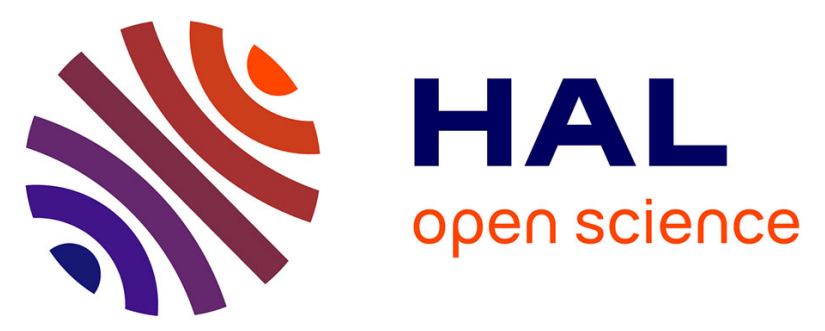

\title{
Cumulative Exposure to Infliximab, But Not Trough Concentrations, Correlate With Rate of Infection
}

Amandine Landemaine, Antoine Petitcollin, Charlène Brochard, Céline

Miard, Marie Dewitte, Eric Le Balc'H, Thomas Grainville, Eric Bellissant, Laurent Siproudhis, Guillaume Bouguen

\section{To cite this version:}

Amandine Landemaine, Antoine Petitcollin, Charlène Brochard, Céline Miard, Marie Dewitte, et al.. Cumulative Exposure to Infliximab, But Not Trough Concentrations, Correlate With Rate of Infection. Clinical Gastroenterology and Hepatology, 2021, 19 (2), pp.288-295.e4. 10.1016/j.cgh.2020.03.018 . hal-02533415

\section{HAL Id: hal-02533415 https://hal-univ-rennes1.archives-ouvertes.fr/hal-02533415}

Submitted on 14 May 2020

HAL is a multi-disciplinary open access archive for the deposit and dissemination of scientific research documents, whether they are published or not. The documents may come from teaching and research institutions in France or abroad, or from public or private research centers.
L'archive ouverte pluridisciplinaire HAL, est destinée au dépôt et à la diffusion de documents scientifiques de niveau recherche, publiés ou non, émanant des établissements d'enseignement et de recherche français ou étrangers, des laboratoires publics ou privés. 


\section{Cumulative Exposure to Infliximab, But Not Trough Concentrations, Correlate With Rate of}

\section{Infection}

Running Title: Infliximab exposure and infection

Amandine Landemaine ${ }^{1}, \mathrm{MD}$, Antoine Petitcollin ${ }^{2}$, MD, Charlène Brochard ${ }^{3}, \mathrm{MD}, \mathrm{PhD}$, Céline Miard $^{1}, \mathrm{MD}$, Marie Dewitte ${ }^{1}$, MD, Eric Le Balc' $h^{1}, \mathrm{MD}$, Thomas Grainville ${ }^{1}, \mathrm{MD}$, Eric Bellissant ${ }^{2}$, MD, PhD, Laurent Siproudhis ${ }^{3}, \mathrm{MD}, \mathrm{PhD}$, Guillaume Bouguen ${ }^{3}, \mathrm{MD}, \mathrm{PhD}$,

${ }^{1}$ CHU Rennes, Univ Rennes, F-35000 Rennes, France

${ }^{2}$ CHU Rennes, Univ Rennes, INSERM, CIC1414, F-35000 Rennes, France

${ }^{3}$ CHU Rennes, Univ Rennes, INSERM, CIC1414, Institut NUMECAN (Nutrition Metabolism and Cancer), F-35000 Rennes, France

\section{Correspondence:}

Guillaume Bouguen, MD, PhD

Service des Maladies de l'Appareil Digestif

2 rue Henri le Guillou 35033 Rennes cedex, FRANCE

Telephone (0033)-2-99-28-43-17 / Fax (0033)-2-99-28-41-89

Email: guillaume.bouguen@chu-rennes.fr

Word count (excluding title page, abstract, references, figures and tables) : 3448

Conflicts of Interest: GB received lecture fees from Abbvie, Ferring, MSD, Takeda and Pfizer and consultant fees from Takeda, Janssen. LS received lecture fees from Abbvie, Ferring and MSD. LS received consultant fees from Takeda and Ferring. CB received lecture fees from Ipsen. AP received lecture fees from Hospira. AL, CM, MD and EB declare no conflict of interest.

Authors' contributions: conception and design of the study: AL, GB ; acquisition of data: AL, CM, $\mathrm{LS}, \mathrm{CB}, \mathrm{MD}, \mathrm{EB}, \mathrm{AP}, \mathrm{GB}$; analysis and interpretation of data AL, GB, AP ; drafting the article: AL GB ; and revising it critically for important intellectual content: all authors. The manuscript was approved by all authors.

Acknowledgment : none

Guarantor of the article: Guillaume BOUGUEN

Source of Funding: None 


\section{ABSTRACT}

Background \& Aims: Infliximab increases the risk of infection in patients with inflammatory bowel diseases (IBD), but there is controversy over the relationship between drug concentration and infections. We aimed to assess factors associated with infection in infliximab-treated patients, including pharmacokinetic features.

Methods: We collected data from 209 patients with IBD (102 men; mean age, 39 y; 159 with Crohn's disease; 54 received combination therapy) who received a infliximab maintenance regimen from November 2016 through April 2017 in France. Data were collected from each infusion visit (total of 640 infusions). Infliximab exposure was estimated based on the area under the curve (AUC) of drug concentration in pharmacokinetic models; individual exposures over the 6-month period were estimated based on the sum of the AUC ( $\Sigma$ AUC).

Results: The mean infliximab trough level was $5.46 \mathrm{mg} / \mathrm{L}$, and the mean $\Sigma$ AUC was $3938 \pm 1427 \mathrm{mg} \mathrm{d} / \mathrm{L}$. A total of 215 infections were collected from the 640 infusion visits; 123 patients (59\%) had at least 1 infection. Factors independently associated with infection after multivariate analysis were smoking (odds ratio [OR], 2.05; $P=.046$ ), IBD flare (OR, 2.71; $P=.006)$, and a high $\Sigma$ AUC of infliximab (above $3234 \mathrm{mg} \mathrm{x} \mathrm{d/L)} \mathrm{(OR,} \mathrm{2.02;} P=.02)$. The $\Sigma$ AUC was higher in patients with an occurrence of infection $(P=.04)$ and correlated with the number of infections $(P=.04)$. Trough concentration of infliximab alone was not associated with infection.

Conclusions: Almost two-thirds of patients treated with infliximab developed an infection; risk was individually correlated with cumulative increase in drug exposure, but not infliximab trough level.

KEY WORDS: tumor necrosis factor, anti-TNF, treatment, CD 


\section{INTRODUCTION}

Although the efficacy of TNF antagonists for the treatment of inflammatory bowel disease (IBD) is widely observed,(1,2) a number of concerns remain regarding potential serious adverse events, especially infections and malignancies.(3) Recently, data from the TREAT registry (The Crohn's Therapy, Resource, Evaluation, and Assessment Tool), a large US-based prospective registry of patients with Crohn's disease (CD), indicated an increased risk of serious infection with infliximab, but not with immunomodulators.(5) In a nationwide population-based study involving French IBD patients,(6) anti-TNF monotherapy was associated with a higher risk of serious, bacterial and mycobacterial infections compared to that in patients unexposed to immunosuppressant as well as patients treated with thiopurine monotherapy. The combination therapy was associated with an even higher risk of serious and opportunistic infection compared to monotherapy with either anti-TNF or thiopurine. This may be explained by the own effect of each immunosuppressant but also by the increase of infliximab exposure related to a lower clearance when added to an immunosuppressant.(7)

Regarding this increased risk of infection with anti-TNF treatment, no clear relationship between the degree of drug exposure and this risk was observed. Therapeutic drug monitoring (TDM) with trough levels of infliximab (TLI) is considered a promising tool to guide dose adjustments of anti-TNF treatment because of a strong association between TLI and treatment efficacy.(8-10) A TLI above 5 $\mu \mathrm{g} / \mathrm{mL}$ during maintenance therapy is consensually admitted to be associated with clinical remission with a possible concentration-response effect according to the outcome measure, regardless of the occurrence of side effects.(11-13) A first report in spondyloarthritis observed an increased risk of a first infectious event for patients treated with infliximab with recurrent high TLI (mean of the last 3 trough $>11.3 \mu \mathrm{g} / \mathrm{mL}$ ).(14) However, that result was not reproduced in a recent cohort study of IBD patients, which observed similar rates of infectious events between patients with TLI above or below 7 $\mu \mathrm{g} / \mathrm{mL}$.(15-16) The latter studies were unfortunately retrospective, with a large amount of lacking data and irregular follow-up that precluded an assessment of the true exposure to the drug. In these studies, the exposure to infliximab was approximated by the TLI. However, the same value of TLI may reflect different exposures to the drug, depending on the treatment modalities (dose and infusion interval). The actual exposure over a treatment period can be estimated by the cumulated area under the concentration curve. To date, the relationship between exposure and the occurrence of infection has never been explored.

Thus, the present study aimed to assess the relationship between exposure to infliximab and the risk of infection in IBD patients under a maintenance regimen as well as predictors of infectious events. 


\section{MATERIAL AND METHODS}

\section{Study POPUlation}

From the $1^{\text {st }}$ November 2016 to the $30^{\text {th }}$ April 2017, data from all adult patients with an established diagnosis of $\mathrm{CD}$ or ulcerative colitis (UC) and treated with infliximab in a single centre were prospectively recorded over this six-month period.(supplementary Method) For the current study, all patients receiving infliximab therapy for at least four months (maintenance regimen) and without infliximab discontinuation during the study period were included.

The disease activity was assessed using the Harvey-Bradshaw Index (HBI) (18) for CD and the Partial Mayo score (PMS) (19) for UC. The clinical remission was defined by an $\mathrm{HBI}<4$ for CD or a PMS < 2 for UC. Active disease for a patient was defined as at least one clinical relapse during the study period, corresponding to at least one recorded $\mathrm{HBI} \geq 4$ or $\mathrm{PMS} \geq 2$.

Infectious events were reported by the patients at each infliximab infusion and were categorized by localization and type of pathogenic organisms according to a systematic questionnaire; rhinolaryngological infections were considered bacterial when an antibiotic treatment was used. Infections related to $\mathrm{CD}$, such as (perianal) abscesses were not considered. All infectious events were reviewed by two investigators $(\mathrm{AL}, \mathrm{GB})$.

The TLI was measured with an in-house enzyme-linked immunosorbent assay (ELISA) fully validated following the FDA guidelines for bioanalytical analysis,(20) just before infliximab administration. The intra-day and inter-day bias (relative error) and precision (coefficient of variation) of the method were below $20 \%$.

Patients were willing to be registered in a prospective database for research use, and the study was approved by the "Commission Nationale Informatique et Liberté" (CNIL No1412467). all authors had access to the study data and reviewed and approved the final manuscript.

\section{EXPOSURE DETERMINATION}

Because of the multiple infliximab infusion modalities that exist in a real-world cohort of IBD patients, the same value of TLI can be found in patients with different exposures as assessed by the area under the concentration-time curve (AUC), as illustrated in Figure 1. Therefore, we estimated the actual exposure to infliximab over the study period by calculating the cumulated AUC ( $\Sigma$ AUC) (21) (supplementary material). The $\Sigma$ AUC over the observation period was obtained by summing the AUCs of all the infusions of the study period in a given individual. AUCs were derived from the individual clearances that can be accurately estimated from the trough concentrations by pharmacokinetic modelling. Therefore, no other concentration measurement was required for AUC estimation. Pharmacokinetic modelling was conducted with Monolix 4.3.3. (Lixoft, France). 


\section{END POINTS}

The primary end point was factors associated with the occurrence of at least one infection over the study period. Secondary end points were factors associated with infectious events between infusions and factors associated with higher $\Sigma$ AUC of infliximab.

\section{STATISTICS}

Quantitative variables were described as the mean \pm standard deviation (S.D.). Categorical variables were presented as counts and percent of the cohort. For group comparisons, univariate analysis was performed using the Wilcoxon test for quantitative variables, and a chi-square test (or Fischer test as appropriate) was used for qualitative variables. All significant variables with a p-value $<0.2$ at the univariate step were integrated into a binary logistic regression model for multivariate analysis. When considering the continuous variables for multivariate analysis, cutoff values were determined by using receiver operating characteristic (ROC) analysis to reduce the risk of bias related to arbitrarily defined cutoffs and to identify the optimal cutoff by using each outcome as a classification variable. A p-value $<0.05$ was considered significant. Statistical analyses were performed using JMP Pro 13.2 software (SAS Institute Inc., Cary, NC). 


\section{RESULTS}

\section{STUDY POPULATION}

A total of 288 adult IBD patients were treated with infliximab during the study period. Among them, 245 patients were treated for at least 4 months at baseline and were under a maintenance regimen. During the 6-month follow-up, 36 patients discontinued infliximab infusions for various reasons and were excluded. None of the 36 patients excluded from this analysis discontinued infliximab for infectious reason. Finally, 209 patients were included in the current study (Figure 2). The baseline characteristics of the patients are depicted in Table 1.

\section{INFLIXIMAB INFUSIONS AND DISEASE OUTCOME DURING THE STUDY PERIOD}

A total of 640 infusions were administered to the 209 patients. Each patient had a mean of $3.1( \pm 0.7)$ infusion visits during a mean follow-up of $24.7( \pm 3.5)$ weeks.

Regarding the scheme of infliximab infusions (Supplementary Table 1), 100 (48\%) patients at baseline were treated with the classical maintenance regimen of $5 \mathrm{mg} / \mathrm{kg}$ every 8 weeks. The treatment regimen was optimized in dose and/or frequency for $64(31 \%)$ patients. A longer dosing interval was ongoing for $42(20 \%)$ patients, and $3(1.4 \%)$ patients had an alternative treatment scheme with a longer interval but a higher dose of infliximab. Among the study population, $176(84 \%)$ patients maintained the same treatment regimen over the study period. Optimization or de-escalation of the infliximab regimen was performed in $17(8.2 \%)$ and $16(7.7 \%)$ patients, respectively.

A sustained clinical remission of IBD was observed in 152 (73\%) patients. Among the 57 (27\%) patients who had at least one period of active IBD (HBI $\geq 4$ or PMS $\geq 3$ ), 9 (16\%) had chronic active disease, whereas $48(84 \%)$ experienced one or more clinical relapses. Clinical disease activity was reported in 83 infusion visits ( $13 \%$ of 640 ), corresponding to mild disease ( $4 \leq \mathrm{HBI}<9$ or $2 \leq \mathrm{PMS}<5$ ), moderate disease $(9 \leq \mathrm{HBI} \leq 12$ or $5 \leq \mathrm{PMS} \leq 7)$ or severe active disease (HBI $>12$ or PMS $>7)$ in $82 \%$ (68/83), 14\% (12/83) and 3.6\% (3/83), respectively. Only five patients received glucocorticoids during the study period. (Supplementary Table 1)

Biological data indicated a mean TLI of $5.5( \pm 4.3) \mu \mathrm{g} / \mathrm{mL}$ and a mean albumin concentration of 43.6 $( \pm 2.8) \mathrm{g} / \mathrm{L}$. The mean $\Sigma$ AUC of infliximab per patient was calculated at $3938( \pm 1427)$ mg/dL.(Supplementary Table 2) A higher $\Sigma$ AUC of infliximab (>3234 mg.d/L) was more frequently observed in recently treated patients $(\mathrm{p}=0.03)$ and in patients receiving combination therapy $(\mathrm{p}=0.02)$. It was also linked to a higher dose of infused infliximab $(\mathrm{p}<0.0001)$, a shorter interval between infusions ( $\mathrm{p}=0.0003)$ and a higher TLI over the observation period $(\mathrm{p}<0.0001)$. (Supplementary Table 3)

\section{INFECTIOUS EVENTS}


A total of 222 infections were reported among the 640 infusion visits and 215 infections were retained, corresponding to 205.7 infections per 100 patient-years. No serious infection was observed. At least one infectious event was documented in 59\% of patients (123/209). Broadly two-thirds of infections were viral (67\%), 29\% were bacterial and $9 \%$ were fungal. The main sites of infection were the ear, nose and throat (ENT - 122 infections [52\%]). Most bacterial infections were related to the ENT for $43 \%(27 / 63)$ of reported infections, and 33\% (21/63) were mucocutaneous. Among the 143 viral infections, two-thirds were related to the ENT (93 [65\%]), 17\% (25) were gastroenteritis and 13\% (18) were influenza or influenza-like illnesses. Fungal infections were urogenital in $75 \%$ (6/8). The characteristics of infections are presented in Table 2.

\section{FACTORS ASSOCIATED WITH INFECTION}

The risk of infection was studied for each patient over the 6-month period (Table 3). The use of systemic corticosteroids was not considered for statistical purposes (only 5 cases). No difference in the rate of infections was observed according to the type of IBD (58\% of patients with CD [92/159] and $62 \%$ of patients with UC [31/50]). After multivariate analysis using dichotomized variables, ongoing smoking ( $\mathrm{OR}=2.05$; CI95[1.01-4.16]; $\mathrm{p}=0.046)$, active disease ( $\mathrm{OR}=2.71$; CI95[1.32-5.54]; $\mathrm{p}=0.0060)$ and a high $\Sigma$ AUC ( $>3234 \mathrm{mg} . \mathrm{d} / \mathrm{L})(\mathrm{OR}=2.02$; CI95[1.11-3.65], $\mathrm{p}=0.020)$ were significantly associated with an increased risk of infection.

Regarding the disease activity, patients with active disease were more likely than patient in clinical remission to have a high $\Sigma$ AUC $>3234 \mathrm{mg}$.d/L (43 versus 13 patients, $\mathrm{p}=0.005$ ). They were also more likely to have an optimized infliximab treatment by either increasing the infused dose or decreasing the interval between two injections $(\mathrm{p}=0.01)$. When stratifying patients based on disease activity, the risk of infection remained significantly associated with a high $\Sigma$ AUC among patients in sustained clinical remission over the study period (61\% of patients with $\Sigma$ AUC $>3234 \mathrm{mg} . \mathrm{d} / \mathrm{L}$ experienced any infection $v s 41 \%, \mathrm{p}=0.01$ ), whereas no significant association between the risk of infection and $\Sigma$ AUC was found in flaring up patients $(\mathrm{p}=0.64)$. There was a strong correlation between the number of infections over the study period and the decile of cAUC (supplementary Figure 3)

Further analysis of the association between $\Sigma$ AUC of infliximab and the different components of infection were performed. The mean $\Sigma$ AUC of infliximab was significantly higher among the group of patients with infections (4105.5 [ \pm 1476.6$]$ versus $3697.9[ \pm 1324.9] \mathrm{mg} . \mathrm{d} / \mathrm{L}, \mathrm{p}=0.04)$ (Figure 3). Moreover, the $\Sigma$ AUC was significantly and positively correlated with the number of infections ( $\mathrm{p}=0.04$ ) (Figure 3), the number of viral infections $(\mathrm{p}=0.04)$ and was also linked to the occurrence of any viral infections $(\mathrm{p}=0.01$ ). The $\Sigma$ AUC was not associated with a higher risk of bacterial infections $(\mathrm{p}=0.26)$, the need for antibiotics $(\mathrm{p}=0.05)$ nor with fungal infections $(\mathrm{p}=0.08)$.

When considering the link between TLI and the occurrence of at least one infection between two infusion visits (Supplementary Figure 2), no association was observed across the 640 infusion visits 
during the study period: mean TLI of $5.46( \pm 4.28) \mathrm{mg} / \mathrm{L}$ among the 435 infusion visits without infectious events and $5.48( \pm 4.30) \mathrm{mg} / \mathrm{L}$ for the 135 infusion visits with the report of an infectious event since the last infusion $(\mathrm{p}=0.83)$. 


\section{DISCUSSION}

In the present study, a higher cumulative exposure to infliximab was significantly associated with a two-fold increase in the risk of infection in IBD patients. Our data are in line with the retrospective report by Bejan-Angoulvant et al.(14) involving 201 infliximab -treated patients with spondyloarthritis. Although they did not assess the $\Sigma$ AUC, authors took into account the mean of the last 3 consecutive TLIs greater than the median $(>11.3 \mu \mathrm{g} / \mathrm{mL})$ that somewhat reflected high exposure to infliximab. In our cohort of 209 IBD patients treated with an infliximab maintenance regimen and followed for a predefined period of time, almost two-thirds of patients (123 [59\%]) experienced at least one infectious event, and 215 infections were reported among the 640 infusion visits. This is in line with the prevalence of infection observed in randomized controlled trials: in the SONIC trial,(22) infections of any type occurred in $46.0 \%$ of infliximab -treated patients.

The first data about infections in IBD patients treated with infliximab from the phase 3 trials suggested there was no increase in infections compared to placebo.(4) Of note, these trials are powered to assess the efficacy but not the safety of the treatment. More recent studies detected an increased risk of serious and opportunistic infections with infliximab treatment compared to treatment with other nonbiological medications in $\mathrm{CD}$, with an even higher risk associated with combination therapy. $(5,6)$ Most available data on infections with infliximab in IBD patients compared infliximab to placebo(4) or to another conventional non-biological medication, $(5,6)$ while the relationship between the risk of infection and the serum infliximab concentrations remains unclear. Contrary to Bejan-Angoulvant et al.,(14) two studies of the safety of infliximab in IBD patients found no increased occurrence of infection with high TLI (> 7 or $8 \mu \mathrm{g} / \mathrm{mL}$ ). $(15,23)$ However, the study design of both studies was not adapted to assess this relationship, and only one value of TLI was used to assess the risk of infection over a four- or six-month period. Interestingly, we found no association between TLI and the occurrence of infections between the two infusions. This suggests that the TLI remains insufficient to assess the long-term drug exposure required to find an association.

Knowing that highly exposed patients have a greater risk of infection suggests de-escalating infliximab dosage (by decreasing the dose or increasing the infusion interval) according to disease activity. A recent retrospective study of IBD patients observed a cumulative rate of relapse of $16 \%$ at one year after infliximab de-escalation, $(24,25)$ which is three times less than after infliximab discontinuation. Furthermore, the authors suggest that a TLI-based strategy for de-escalation among selected patients in deep remission may reduce the risk of low infliximab exposure and relapse. Moreover, the present pharmacokinetic approach suggests some way to adapt infliximab treatment: for a similar TLI, adjustment of the interval rather than the dose infused would result in lower $\Sigma$ AUC.

The main strength of this work was to use the $\Sigma$ AUC to assess infliximab exposure. This is the first study dedicated to investigating the risk of infection with infliximab therapy that used the cumulated 
AUC over a predefined period of time rather than punctual TLI.(14,15) A pharmacokinetic modelling was performed for computation of the $\Sigma$ AUC of infliximab for each patient. Due to the different infliximab treatment modalities, in terms of dose and dosing interval, two patients can have the same TLIs but different levels of drug exposure, corresponding to different values of AUC. Additionally, the AUC improves the assessment of the individual exposure to a drug compared to the trough concentration. Moreover, the $\Sigma$ AUC was currently taken into account to encompass the 6-month period of exposure to the drug, while the TLI only partially reflects the exposure from the last infusion.

Some limitations need to be taken into account. Monoclonal antibodies pharmacokinetics is known to follow a 2-compartment model. However, because our data were constituted only from TLI, the estimation of the distribution phase was not possible. Therefore, we chose to keep a 1-compartment model for the estimation of the AUC, which may lead to overestimate actual drug exposure. However, the objective of this work was to explore whether the exposure could be linked to the risk of infection. In this regard, as long as the method used for the estimation of the AUC is the same in all the patients of the study, the systematic over-estimation bias does not impact the main result, that is a higher cumulated exposure over a period is associated with a higher rate of infection. In addition, the results were similar using other pharmacokinetic models. Contrary to Bejan-Angoulvant and colleagues, the infliximab exposure (AUC) during a period of time was taken into account rather than the first infection following infliximab treatment that may question the causality. Of note, not only the occurrence of an infection but also the number of infections was increased in the present study. The $\Sigma$ AUC has to precede the infection for being the cause of the infection. In this prospective work, infectious events were self-reported, introducing a risk of memory bias. However, in a pooled analysis across the five pivotal phase 3 IBD trials, (4) the infection rate was estimated at $49.8 \%$ in all infliximab -treated IBD patients, which is slightly less than the incidence of $59 \%$ in the current study and underlines the exhaustive declaration of infections. Furthermore, we prospectively collected all types of infections, unlike many studies that focus on the occurrence of serious and/or opportunistic infections with infliximab. $(5,6,26,27)$ The definition of disease activity may be questionable as it was only based on subjective clinical scores and did not take into account biomarkers and endoscopic assessment. Disease activity may be a confounder since it was associated with infection and may drive the physician to optimize infliximab but the $\Sigma$ AUC was associated even stronger with the risk of infection in case of remission. The CRP was not used for that purpose because it is increased by current infection.

In conclusion, high exposure to infliximab increases the risk of infection. There are important implications for patients treated with infliximab. Whereas several recent studies advocate the benefits of infliximab optimization to provide better control of inflammation in IBD, $(13,15,28)$ the potential gain of efficacy should also be weighed against the increased risk of infection. Our findings may 
encourage clinicians to consider drug de-escalation when feasible for patients in clinical remission to avoid infections. 


\section{REFERENCES}

1. Rungoe C, Langholz E, Andersson M, et al. Changes in medical treatment and surgery rates in inflammatory bowel disease: a nationwide cohort study 1979-2011. Gut 2014;63:1607-16.

2. Schnitzler F, Fidder H, Ferrante M, et al. Long-term outcome of treatment with infliximab in 614 patients with Crohn's disease: results from a single-centre cohort. Gut 2009;58:492-500.

3. Hyrich KL, Silman AJ, Watson KD, et al. Anti-tumour necrosis factor alpha therapy in rheumatoid arthritis: an update on safety. Ann Rheum Dis 2004;63:1538-43.

4. Lichtenstein GR, Rutgeerts P, Sandborn WJ, et al. A pooled analysis of infections, malignancy, and mortality in infliximab- and immunomodulator-treated adult patients with inflammatory bowel disease. Am J Gastroenterol 2012;107:1051-63.

5. Lichtenstein GR, Feagan BG, Cohen RD, et al. Serious infection and mortality in patients with Crohn's disease: more than 5 years of follow-up in the TREATTM registry. Am J Gastroenterol 2012;107:1409-22.

6. Kirchgesner J, Lemaitre M, Carrat F, et al. Risk of Serious and Opportunistic Infections Associated With Treatment of Inflammatory Bowel Diseases. Gastroenterology 2018;155:337-46.

7. Hyams JS, Dubinsky M, Rosh J, et al. The effects of concomitant immunomodulators on the pharmacokinetics, efficacy and safety of adalimumab in paediatric patients with Crohn's disease: a post hoc analysis. Aliment Pharmacol Ther. 2019;49:155-64.

8. Adedokun OJ, Sandborn WJ, Feagan BG, et al. Association between serum concentration of infliximab and efficacy in adult patients with ulcerative colitis. Gastroenterology 2014;147:1296-1307

9. Cornillie F, Hanauer SB, Diamond RH, et al. Postinduction serum infliximab trough level and decrease of C-reactive protein level are associated with durable sustained response to infliximab: a retrospective analysis of the ACCENT I trial. Gut 2014;63:1721-27.

10. Lau C, Dubinsky M, Melmed G, et al. The impact of preoperative serum anti-TNF $\alpha$ therapy levels on early postoperative outcomes in inflammatory bowel disease surgery. Ann Surg 2015;261:487-96.

11. Vande Casteele N, Ferrante M, Van Assche G, et al. Trough concentrations of infliximab guide dosing for patients with inflammatory bowel disease. Gastroenterology 2015;148:1320-29.

12. Amiot A, Hulin A, Belhassan M, et al. Therapeutic drug monitoring is predictive of loss of response after de-escalation of infliximab therapy in patients with inflammatory bowel disease in clinical remission. Clin Res Hepatol Gastroenterol 2016;40:90-8. 
13. Roblin X, Boschetti G, Duru G, et al. Distinct Thresholds of Infliximab Trough Level Are Associated with Different Therapeutic Outcomes in Patients with Inflammatory Bowel Disease: A Prospective Observational Study. Inflamm Bowel Dis 2017;23:2048-53.

14. Bejan $\square$ Angoulvant T, Ternant D, Daoued F, et al. Brief Report: Relationship Between Serum Infliximab Concentrations and Risk of Infections in Patients Treated for Spondyloarthritis. Arthritis Rheumatol 2017;69:108-13.

15. Drobne D, Kurent T, Golob S, et al. Success and safety of high infliximab trough levels in inflammatory bowel disease. Scand J Gastroenterol 2018;53:940-46.

16. Greener T, Kabakchiev B, Steinhart AH, et al. Higher Infliximab Levels Are Not Associated With an Increase in Adverse Events in Inflammatory Bowel Disease. Inflamm Bowel Dis. 2018;24:1808-14

17. Satsangi J1, Silverberg MS, Vermeire S, et al. The Montreal classification of inflammatory bowel disease: controversies, consensus, and implications. Gut 2006;55:749-5

18. Harvey RF, Bradshaw JM. A simple index of Crohn's-disease activity. Lancet Lond Engl $1980 ; 1: 514$.

19. Lewis JD, Chuai S, Nessel L, et al. Use of the Non-invasive Components of the Mayo Score to Assess Clinical Response in Ulcerative Colitis. Inflamm Bowel Dis 2008;14:1660-66.

20. Guidance for industry: bioanalytical method validation. www.fda.gov.

21. Ternant D, Passot C, Aubourg A, et al. Model-Based Therapeutic Drug Monitoring of Infliximab Using a Single Serum Trough Concentration. Clin Pharmacokinet 2018;57:1173-84.

22. Colombel JF, Sandborn WJ, Reinisch W, et al. Infliximab, azathioprine, or combination therapy for Crohn's disease. N Engl J Med 2010;362:1383-95.

23. Greener T, Kabakchiev B, Steinhart AH, et al. Higher Infliximab Levels Are Not Associated With an Increase in Adverse Events in Inflammatory Bowel Disease. Inflamm Bowel Dis 2018;24:1808-14.

24. Lucidarme C, Petitcollin A, Brochard C, et al. Predictors of relapse following infliximab deescalation in patients with inflammatory bowel disease: the value of a strategy based on therapeutic drug monitoring. Aliment Pharmacol Ther 2019;49:147-54.

25. Petitcollin A, Brochard C, Siproudhis L, et al. Pharmacokinetic parameters of infliximab influence the rate of relapse after de-escalation in adults with inflammatory bowel diseases. Clin Pharmacol Ther. In press 


\section{Journal Pre-proof}

26. Ford AC, Peyrin-Biroulet L. Opportunistic infections with anti-tumor necrosis factor- $\alpha$ therapy in inflammatory bowel disease: meta-analysis of randomized controlled trials. Am J Gastroenterol 2013;108:1268-76.

27. Nyboe Andersen N, Pasternak B, Friis-Møller N, et al. Association between tumour necrosis factor- $\alpha$ inhibitors and risk of serious infections in people with inflammatory bowel disease: nationwide Danish cohort study. BMJ 2015;350:h2809.

28. Davidov Y, Ungar B, Bar-Yoseph H, et al. Association of Induction Infliximab Levels With Clinical Response in Perianal Crohn's Disease. J Crohns Colitis 2017;11:549-55. 


\section{TABLES AND FIGURES LEGENDS}

Table 1: Patients' characteristics at baseline

Table 2: Prevalence and type of infections reported by patients treated with infliximab during the study

Table 3: Factors associated with infection over the 6-month period by univariate and multivariate analyses

Figure 1: Comparative concentration-time profiles of infliximab and corresponding cumulated exposure. The upper plot shows the simulated concentration-versus-time curves in a 70-kg patient receiving either $5 \mathrm{mg} / \mathrm{kg}$ q6w (full line) or $10 \mathrm{mg} / \mathrm{kg}$ q8w (dashed line). The lower plot shows the corresponding cumulative area under the curve (AUC) for each regimen. Note that the Cmin values are equivalent with both regimens, whereas the cumulative exposure is higher with the $10 \mathrm{mg} / \mathrm{kg} \mathrm{q} 8 \mathrm{w}$ regimen.

Figure 2: Flow chart

Figure 3: Association of the 6-month cumulative area under the concentration-time curve of infliximab exposure ( $\Sigma$ AUC) and the risk of infection. The histograms show the association of the mean $\Sigma$ AUC with the risk of any infection $(\mathrm{p}=0.04)(\mathbf{A})$ and with the number of infections reported $(\mathrm{p}=0.04)(\mathbf{B})$.

Supplementary Figure 1: Correlation between several methods of area under the curve (AUC) estimation. AUC1 according to the Fasanmade 2-compartement model (Fasanmade AA et al, Clin Ther.2011;33:946-64) AUC2 according to the Buurman 2-compartment model (Buurman DJ, et al. Aliment Pharmacol Ther. 2015;42:529-39) AUC3 according to the Ternant 1-compartment model (Ternant D, et al. Clin Pharmacokinet 2018; 57:1173-84). AUC4 and 5 correspond to homemade 1compartment model. (Abbreviation: Corr., correlation using the spearman test)

Supplementary Figure 2: Association between infections and trough concentration of infliximab

Supplementary Figure 3: Correlation between the number of infections over the study period and the decile of cumulative area under the curve (cAUC), showing a quantitative link between higher cAUC and the cumulated 6-months number of infections (statistic performed by Poisson regression, $\mathrm{p}<0,001$ for all)

Supplementary Table 1: Infliximab treatment regimen variation over the study period

Supplementary Table 2: Biology over the study period

Supplementary Table 3: Factors associated with a high 6-month cumulative area under the curve (AUC) of Infliximab 
Infliximab exposure and infection

Journal Pre-proof

Supplementary Method: additional description for study population (data) and exposure determination 
Table 1 : Patients' characteristics at baseline

\begin{tabular}{|c|c|}
\hline & $\mathrm{N}=\mathbf{2 0 9}$ \\
\hline Sex (Male / Female $)-\mathrm{n}(\%)$ & $102(49) / 107(51)$ \\
\hline Age - mean $( \pm \mathrm{SD})$ & $39( \pm 14)$ \\
\hline Type of IBD (CD / UC) - n (\%) & $159(76) / 50(24)$ \\
\hline Duration of IBD (years) - mean $( \pm$ SD) & $12.4( \pm 7.7)$ \\
\hline $\mathrm{BMI}-$ mean $( \pm \mathrm{SD})$ & $25.0( \pm 5.2)$ \\
\hline Smoking (Smokers / Ex-smokers / No-smokers) $-\mathrm{n}(\%)$ & $50(24) / 40(19) / 119(57)$ \\
\hline IBD Phenotype & $\mathbf{N}=\mathbf{2 0 9}$ \\
\hline $\mathrm{A} 1 \leq 16$ years $-\mathrm{n}(\%)$ & $34(16)$ \\
\hline $\mathrm{A} 2 \geq 17$ years $\leq 40$ years $-\mathrm{n}(\%)$ & $148(71)$ \\
\hline A $3>40$ years $-\mathrm{n}(\%)$ & $27(13)$ \\
\hline CD characteristics at the time of inclusion & $\mathbf{N}=\mathbf{1 5 9}$ \\
\hline $\mathrm{B} 1$ inflammatory $-\mathrm{n}(\%)$ & $100(62)$ \\
\hline $\mathrm{B} 2$ stricturing $-\mathrm{n}(\%)$ & $33(21)$ \\
\hline B3 penetrating $-\mathrm{n}(\%)$ & $26(16)$ \\
\hline $\mathrm{p}$ perianal disease $-\mathrm{n}(\%)$ & $60(37)$ \\
\hline L1 ileal $-\mathrm{n}(\%)$ & $31(19)$ \\
\hline $\mathrm{L} 2$ colonic $-\mathrm{n}(\%)$ & $38(24)$ \\
\hline L3 ileocolonic - n (\%) & $90(57)$ \\
\hline L4 isolated upper disease $-\mathrm{n}(\%)$ & $20(13)$ \\
\hline UC characteristics at the time of inclusion & $\mathbf{N}=\mathbf{5 0}$ \\
\hline E1 ulcerative proctitis - n (\%) & $10(20)$ \\
\hline E2 left side $\mathrm{UC}-\mathrm{n}(\%)$ & $19(38)$ \\
\hline E3 extensive $\mathrm{UC}-\mathrm{n}(\%)$ & $21(42)$ \\
\hline Prior Surgery & $\mathbf{N}=\mathbf{2 0 9}$ \\
\hline Previous bowel surgery $-\mathrm{n}(\%)$ & $54(26)$ \\
\hline Previous perineal surgery $-\mathrm{n}(\%)$ & $50(24)$ \\
\hline Medical treatment & $\mathbf{N}=\mathbf{2 0 9}$ \\
\hline IFX duration at inclusion (years) - mean $( \pm S D)$ & $5.0( \pm 3.7)$ \\
\hline Combination therapy with IS - n (\%) & $54(26)$ \\
\hline - $\quad$ Methotrexate $-\mathrm{n}(\%)$ & $12(6)$ \\
\hline - $\quad$ Thiopurine $-\mathrm{n}(\%)$ & $42(20)$ \\
\hline
\end{tabular}

Abbreviations : BMI. Body Mass Index ; CD. Crohn's Disease ; IFX. Infliximab ; IS. Immunosuppressant ; SD. Standard deviation ; UC. Ulcerative Colitis 
Table 2 : Prevalence and type of infections reported by patients treated with infliximab during the study

\begin{tabular}{|c|c|c|}
\hline \multicolumn{3}{|l|}{ Any infections } \\
\hline \multirow[t]{2}{*}{$\geq 1$ Infectious event $-\mathrm{n}(\%)$} & $205(32)$ & \\
\hline & & $\mathrm{N}=209$ patients \\
\hline Infections per patient - mean $( \pm S D)$ & $1( \pm 1.1)$ & \\
\hline Patients concerned by infections $-\mathrm{n}(\%)$ & $123(59)$ & \\
\hline 1 infection & $59(28)$ & \\
\hline 2 infections & $39(19)$ & \\
\hline 3 infections & $22(11)$ & \\
\hline 4 infections & $3(1.4)$ & \\
\hline Antibiotic therapy & $46(22)$ & \\
\hline \multirow{2}{*}{$\geq 2$ antibiotic therapies } & $8(3.8)$ & \\
\hline & e & $\mathrm{N}=215$ infections \\
\hline \multirow{4}{*}{$\begin{array}{l}\text { Bacterial infection } \\
\text { Viral infections - } \\
\text { Fungal infections - } \\
\text { Site of infection - } \\
\end{array}$} & $63(29)$ & \\
\hline & $143(67)$ & \\
\hline & $9(4.1)$ & \\
\hline & & \\
\hline ENT & $122(57)$ & \\
\hline Gastrointestinal & $26(12)$ & \\
\hline Cutaneo-mucosal & $26(12)$ & \\
\hline Influenza or influenza-like illnesses & $18(8.4)$ & \\
\hline Urogenital & $10(4.7)$ & \\
\hline Dental & $5(2.3)$ & \\
\hline Ophtalmic & $5(2.3)$ & \\
\hline Pulmonary & $3(1.4)$ & \\
\hline
\end{tabular}

Abbreviations : ENT, otorhinolaryngological 
Table 3 : Factors associated with infection over the 6-month period by univariate and multivariate analyses

\begin{tabular}{|c|c|c|c|}
\hline \multirow[t]{2}{*}{ Covariates } & \multirow{2}{*}{$\begin{array}{c}\text { Univariate analysis } \\
\text { p value }\end{array}$} & \multicolumn{2}{|c|}{ Multivariate analysis } \\
\hline & & OR $[95 \% \mathrm{CI}]$ & $\mathrm{p}$ value \\
\hline Sex (Male) & 0.57 & & \\
\hline BMI & 0.77 & & \\
\hline Smoker & 0.06 & $2.05[1.01-4.16]$ & 0.046 \\
\hline IBD Phenotype & & & \\
\hline Type of IBD (CD / UC) & 0.60 & & \\
\hline Montreal A (reference A1) & 0.37 & & \\
\hline Crohn's Disease & & & \\
\hline Montreal B & 0.27 & & \\
\hline Montreal L & 0.80 & & \\
\hline Montreal L4 & 0.45 & & \\
\hline Montreal p & 0.37 & & \\
\hline$\underline{\text { Ulcerative colitis }}$ & & & \\
\hline Montreal E & 0.53 & & \\
\hline Prior Surgery & & & \\
\hline Previous bowel surgery & 0.33 & & \\
\hline Previous perineal surgery & 0.24 & & \\
\hline Medical treatment & & & \\
\hline Duration of IFX therapy & 0.28 & & \\
\hline Combination therapy with IS & 0.8 & & \\
\hline Disease Activity ( $\geq 1$ relapse) & 0.001 & $2.71[1.32-5.54]$ & 0.006 \\
\hline Biology & & & \\
\hline Mean albumin concentration & 0.75 & & \\
\hline$\Sigma$ AUC for IFX (> $3234 \mathrm{mg} . \mathrm{h} / \mathrm{L}$ for MA) & 0.04 & $2.02[1.11-3.65]$ & 0.020 \\
\hline
\end{tabular}

Abbreviations : BMI, Body Mass Index ; CD, Crohn's Disease ; IBD, inflammatory bowel disease ; IFX, Infliximab ; IS, Immunosuppressant ; MA, Multivariate Analysis ; SD, Standard deviation ; TLI, trough concentration of infliximab ; UC, Ulcerative Colitis ; $\Sigma$ AUC : 6-month cumulative Area Under the Concentration versus time curves 
Figure 2 : Flow chart

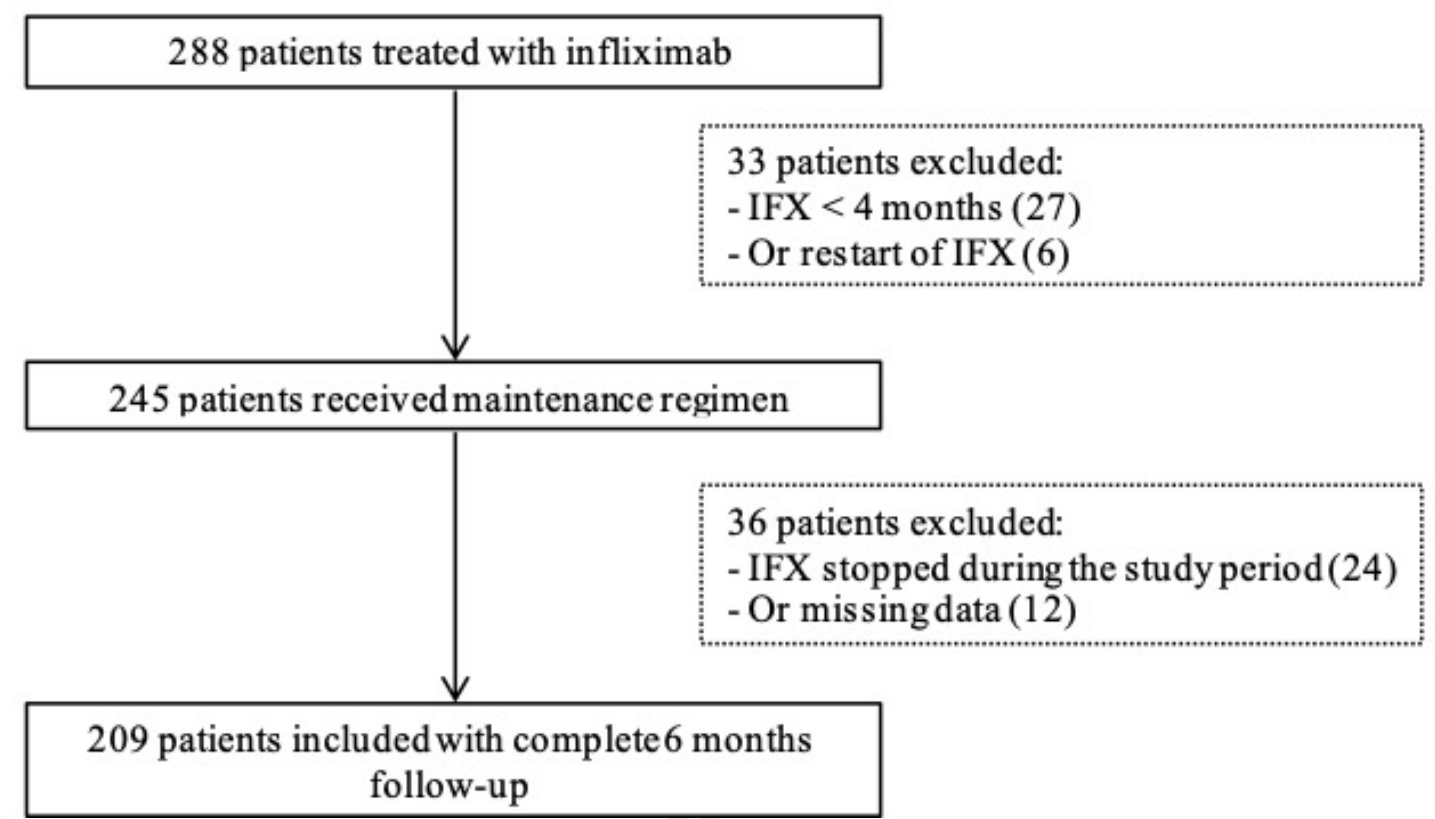


A

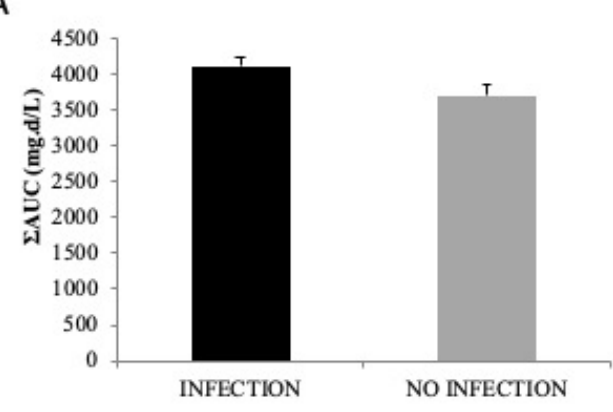
$100 \%$

C

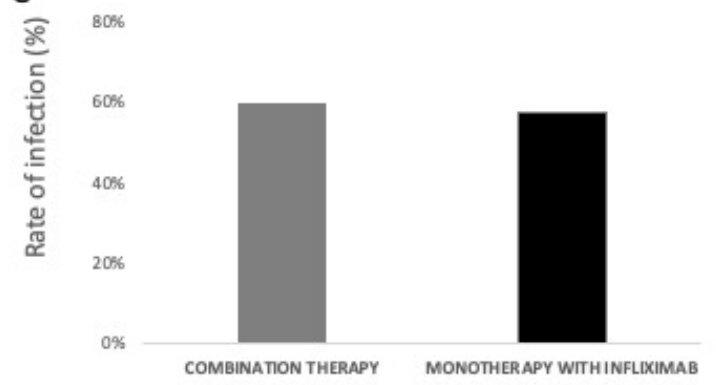

\section{B EAUC (mg-d/L)}

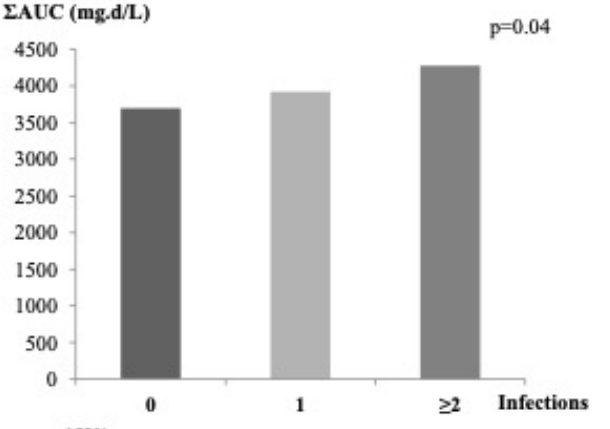

D

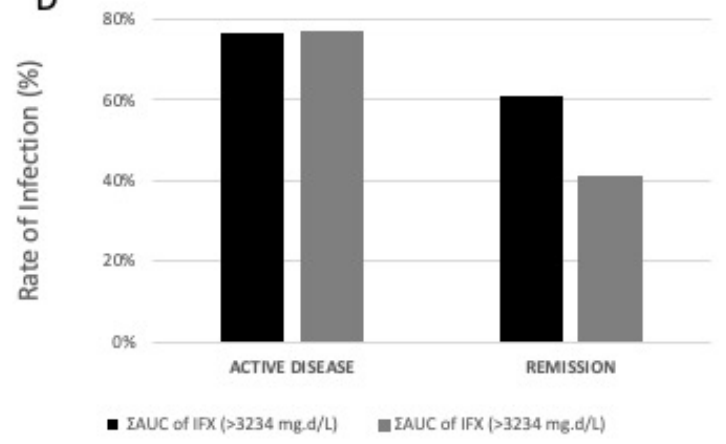


Figure 1: Comparative concentration-time profiles of infliximab and corresponding cumulated exposure. The upper plot (A) shows the simulated concentration-versus-time curves in a 70-kg patient receiving either $5 \mathrm{mg} / \mathrm{kg}$ q6w (full line) or $10 \mathrm{mg} / \mathrm{kg} \mathrm{q8w}$ (dashed line). The lower plot (B) shows the corresponding cumulative AUC for each regimen. Note that the Cmin values are equivalent with both regimens, whereas the cumulative exposure is higher with the $10 \mathrm{mg} / \mathrm{kg} \mathrm{q} 8 \mathrm{w}$ regimen.

A

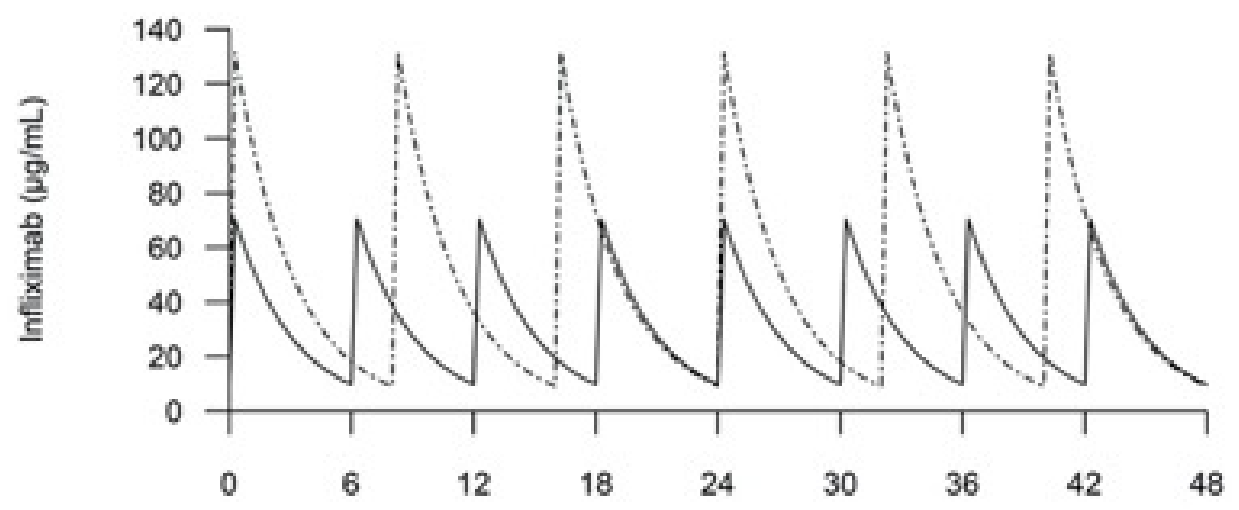

B

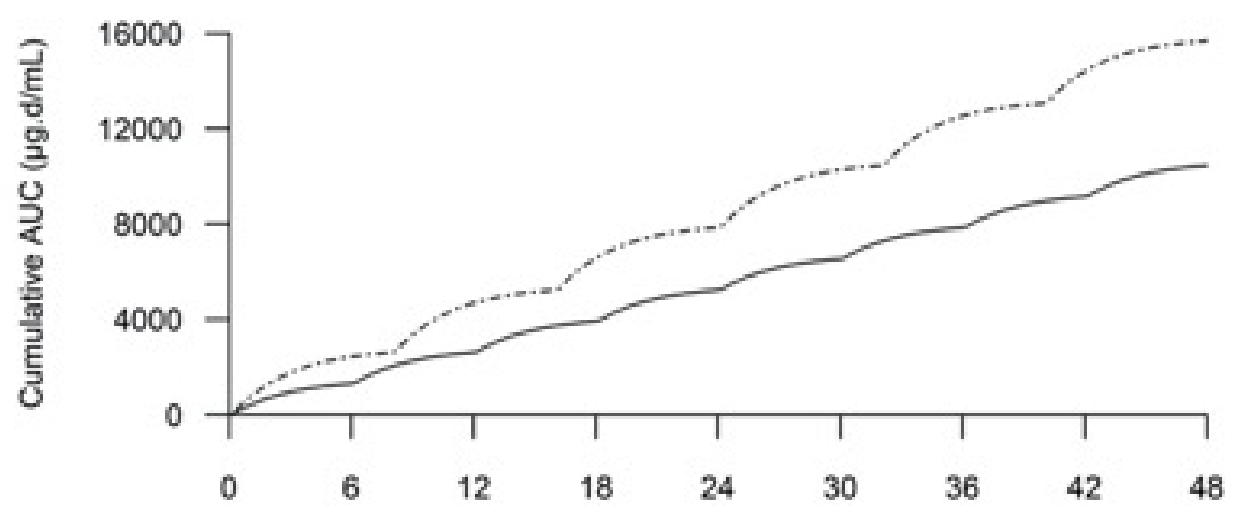

Time (weeks) 


\section{Journal Pre-proof}

Supplementary Figure 1 : Correlation between several methods of AUC estimation. AUC1 according to the Fasanmade 2-compartement model (Fasanmade AA et al, Clin Ther.2011;33:946-64) AUC2 according to the Buurman 2-compartment model (Buurman DJ, et al. Aliment Pharmacol Ther. 2015;42:529-39) AUC3 according to the Ternant 1-compartment model (Ternant D, et al. Clin Pharmacokinet 2018; 57:1173-84). AUC4 and 5 correspond to homemade 1-compartment model. (Abbreviation : Corr., correlation using the spearman test)

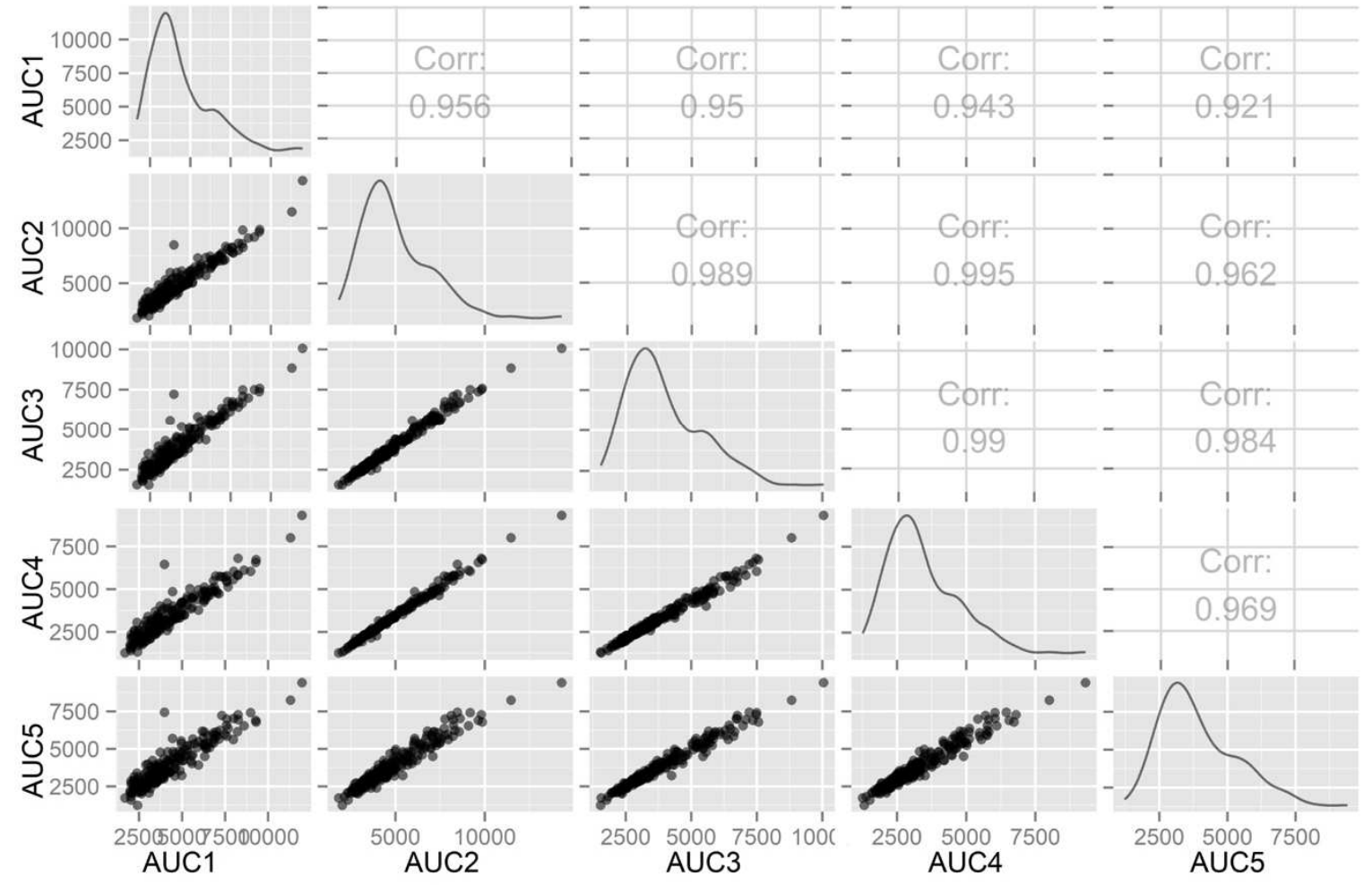


Supplementary Figure 2: Association between infections and trough concentration of infliximab

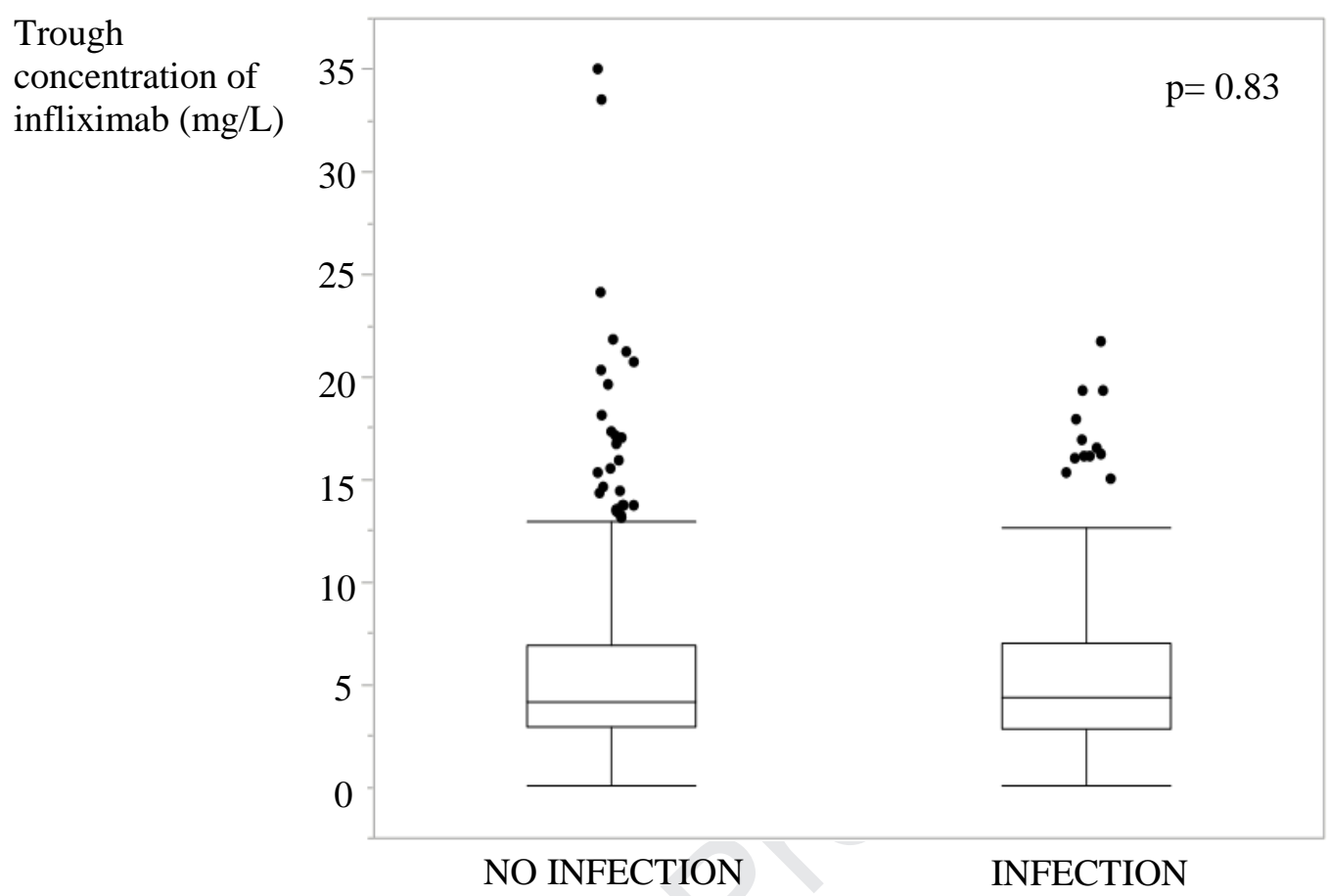




\section{Journal Pre-proof}

Supplementary Figure 3: Correlation between the number of infections over the study period and the decile of cumulative area under the curve (cAUC), showing a quantitative link between higher cAUC and the cumulated 6-months number of infections (statistic performed by Poisson regression, $\mathrm{p}<0,001$ for all)
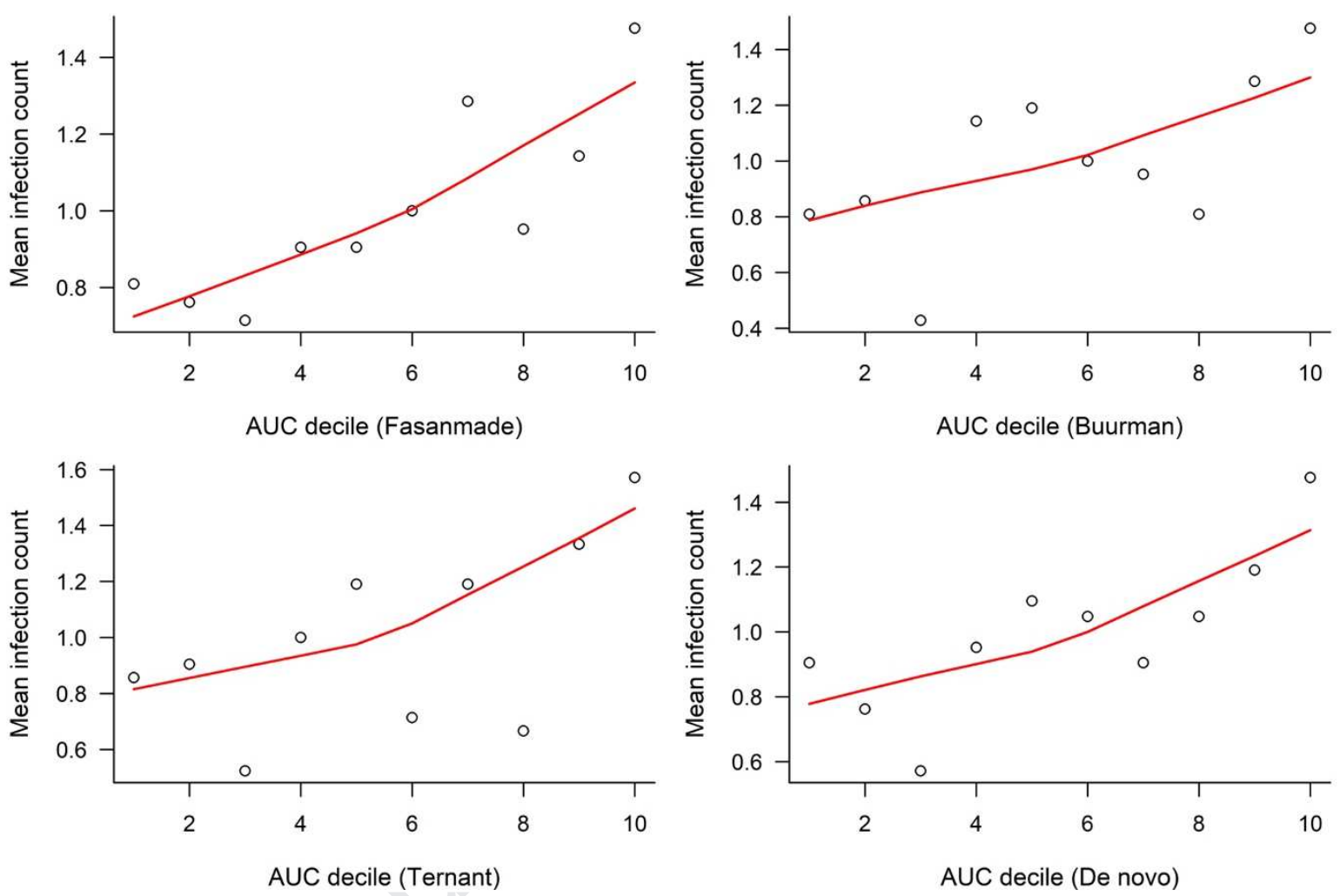
Supplementary Table 1 : Infliximab treatment regimen variation over the study period

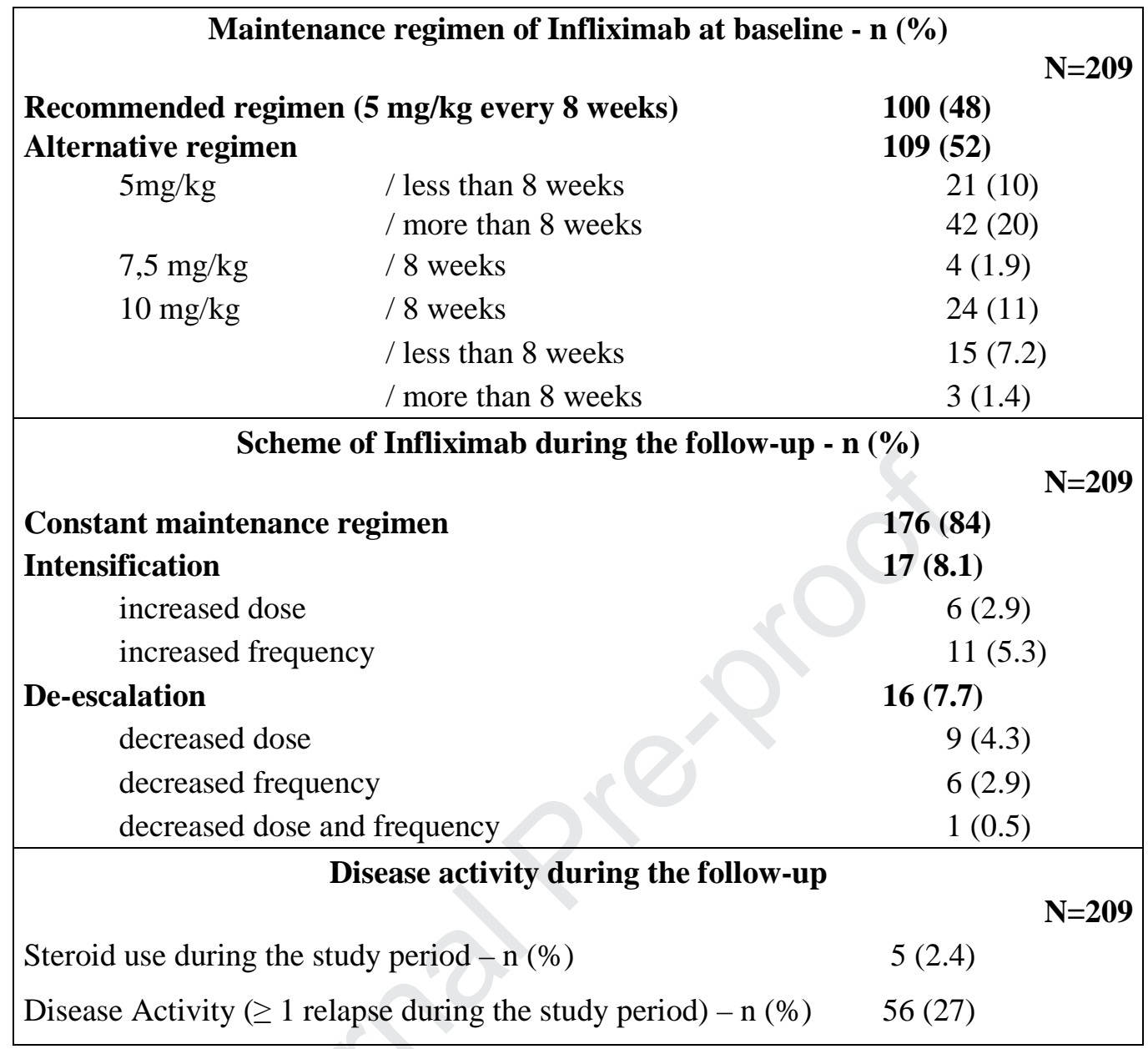


Supplementary Table 2 : Biology over the study period

\begin{tabular}{|l|l|}
\hline Hemoglobin $(\mathrm{g} / \mathrm{dl})-$ mean $( \pm \mathrm{SD})$ & $14.1( \pm 1.4)$ \\
PMNs $\left(\mathrm{UI} / \mathrm{mm}^{3}\right)-$ mean $( \pm \mathrm{SD})$ & $3936( \pm 1400)$ \\
Lymphocytes $\left(\mathrm{UI} / \mathrm{mm}^{3}\right)-$ mean $( \pm \mathrm{SD})$ & $2268( \pm 844)$ \\
Platelets $\left(\mathrm{UI} / \mathrm{mm}^{3}\right)-$ mean $( \pm \mathrm{SD})$ & $287231.5( \pm 74543)$ \\
CRP $(\mathrm{mg} / \mathrm{L})-$ mean $( \pm \mathrm{SD})$ & $4.3( \pm 6.1)$ \\
Albumin - mean $( \pm \mathrm{SD})$ & $43.6( \pm 2.8)$ \\
IFX trough concentration $(\mathrm{mg} / \mathrm{L})-$ mean $( \pm \mathrm{SD})$ & $5.46( \pm 4.30)$ \\
IAUC of IFX $($ mg.d/L) - mean $( \pm \mathrm{SD})$ & $3938( \pm 1427)$ \\
\hline
\end{tabular}

Abbreviations : AUC : Area Under the concentration versus time Curve ; CRP, C-Reactive protein ; IFX, Infliximab ;PNN, polymorphonuclear neurophils; SD, Standard deviation 
Supplementary Table 3 : Factors associated with a high 6-month cumulative AUC of Infliximab

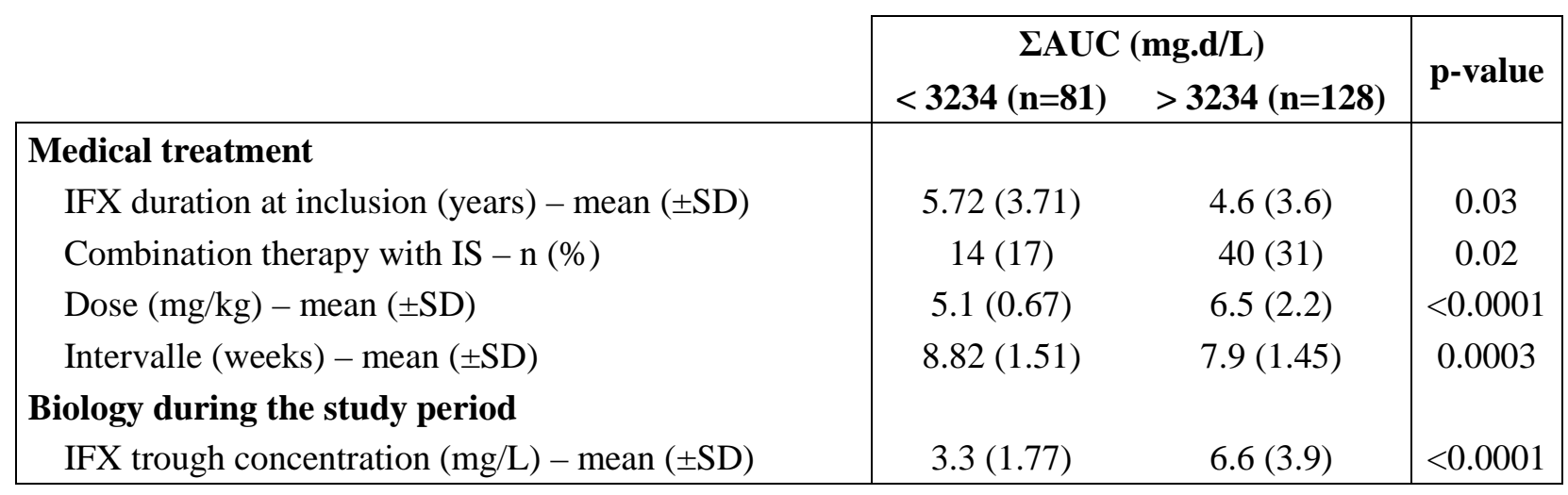

Abbreviations: IBD, inflammatory bowel disease; IFX, Infliximab; IS, Immunosuppressant; AAUC, 6month cumulative Area Under the concentration versus time Curve; SD, standard deviation 
$\underline{\text { Supplementary Method }}$

\section{$\underline{\text { Additional information of study population }}$}

The following key data were recorded at inclusion: sex, age at diagnosis, height, weight, smoking habits, luminal CD and UC phenotypes according to the Montreal classification (17) at diagnosis, start date for IFX treatment, previous and concomitant medications (including steroids, 5-ASA and immunosuppressants) and surgical history.

During the study period, clinical and biological data were prospectively recorded at each IFX infusion: the dose of IFX received at the last and current visits $(\mathrm{mg} / \mathrm{kg}$ ), the interval between infusions (weeks), the clinical disease activity indices, the occurrence of infections since the last visit infusion and the use of antibiotics, the trough concentration of IFX $(\mathrm{mg} / \mathrm{L})$, the haemogram, the C-reactive-protein (CRP, $\mathrm{mg} / \mathrm{L})$ and albumin $(\mathrm{g} / \mathrm{L})$ concentrations.

\section{additional description of exposure determination}

Because of the multiple IFX infusion modalities that exist in a real-world cohort of IBD patients, the same value of TLI can be found in patients with different exposures as assessed by the area under the concentration-time curve (AUC), as illustrated in Figure 1. Therefore, we estimated the actual exposure to IFX over the study period by calculating the cumulated AUC ( $\Sigma$ AUC). A Bayesian estimation of individual pharmacokinetic parameters at each infusion interval was performed using a previously published model.(19) Briefly, this model consisted of a one-compartment compartment model with first order elimination; the estimation of the individual parameters was refined by the use of the relevant individual characteristics that were identified to influence the value of the pharmacokinetic parameters (covariates). The covariate model included the influence of body weight and gender on the value of the clearance. An inter-infusion variability was added to account for the changes in clearance during the observation period. The AUC representing the exposure over an infusion interval was derived from the dose/clearance ratio. This method is particularly convenient when only trough concentrations are available, because the clearance can be reliably estimated from the trough concentration by compartment modelling. Therefore, no measurement other than the trough concentration is necessary to estimate the total clearance and then determine the AUC. The individual pharmacokinetic parameters (clearance and volume of distribution) were estimated by determination of the Empirical Bayes Estimates (EBE) which represent the more probable values of the individual parameters using a Bayesian approach. The $\Sigma$ AUC over the observation period was obtained by summing the AUCs of all the infusions of the study period in a given individual. Pharmacokinetic modelling was conducted with Monolix 4.3.3. (Lixoft, France). Of note, the 1-compartment model used for AUC calculation may lead to a systematic overestimation of the cAUC, because monoclonal 
antibodies are known to follow a 2-compartment model; however, since only trough concentrations were available, the distribution process could not be reliably estimated. Other published models (including 2-compartment models) were tested and were well correlated (Supplementary Figure 1).” 
What You Need to Know

Background: Infliximab increases the risk of infection in patients with inflammatory bowel diseases (IBD), but there is controversy over the relationship between drug concentration and infections.

Findings: Almost two-thirds of patients treated with infliximab developed an infection; risk correlated with cumulative increase in drug exposure but not infliximab trough level.

Implications for patient care: Patients who smoke, have IBD flares, or receive high doses of infliximab for treatment of IBD should be carefully monitored for infections. 